\title{
Interval-valued functional integro-differential equations
}

\author{
Ngo Van Hoa' ${ }^{1}$ Nguyen Dinh Phu ${ }^{2}$, Tran Thanh Tung ${ }^{3 *}$ and Le Thanh Quang ${ }^{2}$
}

\author{
"Correspondence: \\ tttung@ttn.edu.vn; \\ thanhtung_bmt@yahoo.com \\ ${ }^{3}$ Faculty of Natural Science and \\ Technology, Tay Nguyen University, \\ 567 Le Duan Road, Buon Ma Thuot \\ City, Daklak Province, Vietnam \\ Full list of author information is \\ available at the end of the article
}

\begin{abstract}
This paper is devoted to studying the local and global existence and uniqueness results for interval-valued functional integro-differential equations (IFIDEs). In the paper, for the local existence and uniqueness, the method of successive approximations is used and for the global existence and uniqueness, the contraction principle is a good tool in investigating. Some examples are given to illustrate the results.
\end{abstract}

MSC: $34 \mathrm{G} 20 ; 34 \mathrm{~A} 12 ; 34 \mathrm{~K} 30$

Keywords: interval-valued differential equations; generalized Hukuhara derivative; functional integro-differential equations

\section{Introduction}

Functional differential equations (or, as they are called, delay differential equations) play an important role in an increasing number of system models in biology, engineering, physics and other sciences. There exists an extensive amount of literature dealing with functional differential equations and their applications; the reader is referred to the monographs [1-6] and the references therein.

The set-valued differential and integral equations are an important part of the theory of set-valued analysis. They have an important value in theory and application in control theory; and they were studied in 1969 by De Blasi and Iervolino [7]. Recently, setvalued differential equations have been studied by many authors due to their application in many areas. For many results in the theory of set-valued differential and integral equations, the readers can be referred to the following books and papers [8-23] and the references therein. The interval-valued analysis and interval-valued differential equations (IDEs) are the particular cases of the set-valued analysis and set differential equations, respectively. In many cases, when modeling real-world phenomena, information about the behavior of a dynamic system is uncertain, and we have to consider these uncertainties to gain more models. The interval-valued differential and integro-differential equations can be used to model dynamic systems subject to uncertainties. Recently, many works have been done by several authors in the theory of interval-valued differential equations (see, e.g., [24-26]). These equations can be studied with a framework of the Hukuhara derivative [27]. However, it causes that the solutions have increasing length of their values. Stefanini and Bede [26] proposed to consider the so-called strongly generalized derivative of interval-valued functions. The interval-valued differential equations with this deriva-

○2014 Hoa et al.; licensee Springer. This is an Open Access article distributed under the terms of the Creative Commons Attribution License (http://creativecommons.org/licenses/by/2.0), which permits unrestricted use, distribution, and reproduction in any medium, provided the original work is properly cited. 
tive can have solutions with decreasing length of their values. This approach was the starting point for the topic of interval-valued differential equations (see [24, 25]). Besides that, some very important extensions of the interval-valued differential equations are the set differential equations (see $[6,8,11-14,16,18,20,23,28-31]$ ).

The connection between the fuzzy analysis and the interval analysis is very well known (Moore and Lodwick [32]). Interval analysis and fuzzy analysis were introduced as an attempt to handle interval uncertainty that appears in many mathematical or computer models of some deterministic real-world phenomena. Based on the results in [33], there are some very important extensions, and the development related to the subject of the present paper is in the field of fuzzy sets, i.e., fuzzy calculus and fuzzy differential equations under generalized Hukuhara derivative. Recently, several works, e.g., $[5,9,10,30,34-45]$, have been done on fuzzy differential equations and fuzzy integrodifferential equations, the fuzzy stochastic differential equations [46-51], fractional fuzzy differential equations [30,52-55], and some methods for solving fuzzy differential equations $[56,57]$.

In the papers [24-26], one can find the studies on interval-valued differential equations under generalized Hukuhara differentiability, i.e., equations of the form

$$
D_{H}^{g} X(t)=F(t, X(t)), \quad X\left(t_{0}\right)=X_{0} \in K_{C}(\mathbb{R}), \quad t \in\left[t_{0}, t_{0}+p\right],
$$

where $D_{H}^{g}$ denotes two kinds of derivatives, namely the classical Hukuhara derivative and the second-type Hukuhara derivative (generalized Hukuhara differentiability). The existence and uniqueness of a Cauchy problem is then obtained under an assumption that the coefficients satisfy a condition with the Lipschitz constant (see [26]). The proof is based on the application of the Banach fixed point theorem. In [25], under the generalized Lipschitz condition, Malinowski obtained the existence and uniqueness of solutions to both kinds of IDEs. In this paper, we study two kinds of solutions to IFIDEs. The different types of solutions to IFIDEs are generated by the usage of two different concepts of interval-valued derivative. Furthermore, in [5], Lupulescu established the local and global existence and uniqueness results for fuzzy functional differential equations. Malinowski [6] studied the existence and uniqueness result of solution to the delay setvalued differential equations under the condition that the right-hand side of an equation is Lipschitzian in the functional variable. Inspired and motivated by the results of Stefanini and Bede [26], Malinowski [24, 25] and Lupulescu [5], we consider the intervalvalued functional integro-differential equations under generalized Hukuhara derivative. The paper is organized as follows. As preliminaries, we recall some basic concepts and notations about interval analysis and interval-valued differential equations. In Section 3, we present the local and global existence and uniqueness theorem of solution of IFIDEs under generalized Hukuhara derivatives. In the last section, we give some examples as simple illustrations of the theory of interval-valued functional integro-differential equations.

\section{Preliminaries}

Let us denote by $K_{C}(\mathbb{R})$ the set of any nonempty compact intervals of the real line $\mathbb{R}$. The addition and scalar multiplication in $K_{C}(\mathbb{R})$ are defined as usual, i.e., for $A, B \in K_{C}(\mathbb{R})$, 
$A=[\underline{A}, \bar{A}], B=[\underline{B}, \bar{B}]$, where $\underline{A} \leq \bar{A}, \underline{B} \leq \bar{B}$, and $\lambda \geq 0$, then we have

$$
A+B=[\underline{A}+\underline{B}, \bar{A}+\bar{B}], \quad \lambda A=[\lambda \underline{A}, \lambda \bar{A}] \quad(-\lambda A=[-\lambda \bar{A},-\lambda \underline{A}]) .
$$

Furthermore, let $A \in K_{C}(\mathbb{R}), \lambda_{1}, \lambda_{2}, \lambda_{3}, \lambda_{4}, \in \mathbb{R}$ and $\lambda_{3} \lambda_{4} \geq 0$, then we have $\lambda_{1}\left(\lambda_{2} A\right)=$ $\left(\lambda_{1} \lambda_{2}\right) A$ and $\left(\lambda_{3}+\lambda_{4}\right) A=\lambda_{3} A+\lambda_{4} A$. Let $A, B \in K_{C}(\mathbb{R})$ as above, the Hausdorff metric $H$ in $K_{C}(\mathbb{R})$ is defined as follows:

$$
H[A, B]=\max \{|\underline{A}-\underline{B}|,|\bar{A}-\bar{B}|\} .
$$

It is known that $\left(K_{C}(\mathbb{R}), H\right)$ is a complete, separable and locally compact metric space. We define the magnitude and the length of $A \in K_{C}(\mathbb{R})$ by

$$
H[A, 0]=\|A\|=\max \{|\underline{A}|,|\bar{A}|\}, \quad \operatorname{len}(A)=\bar{A}-\underline{A},
$$

respectively, where 0 is the zero element of $K_{C}(\mathbb{R})$ which is regarded as one point.

The Hausdorff metric (2.1) satisfies the following properties:

$$
\begin{aligned}
& H[A+C, B+C]=H[A, B] \text { and } H[A, B]=H[B, A], \\
& H[A+B, C+D] \leq H[A, C]+H[B, D], \\
& H[\lambda A, \lambda B]=|\lambda| H[A, B]
\end{aligned}
$$

for all $A, B, C, D \in K_{C}(\mathbb{R})$ and $\lambda \in \mathbb{R}$. Let $A, B \in K_{C}(\mathbb{R})$. If there exists an interval $C \in K_{C}(\mathbb{R})$ such that $A=B+C$, then we call $C$ the Hukuhara difference of $A$ and $B$. We denote the interval $C$ by $A \ominus B$. Note that $A \ominus B \neq A+(-) B$. It is known that $A \ominus B$ exists in the case len $(A) \geq \operatorname{len}(B)$. Besides that, we can see the following properties for $A, B, C, D \in K_{C}(\mathbb{R})$ (see [24]):

- If $A \ominus B, A \ominus C$ exist, then $H[A \ominus B, A \ominus C]=H[B, C]$

- If $A \ominus B, C \ominus D$ exist, then $H[A \ominus B, C \ominus D]=H[A+D, B+C]$

- If $A \ominus B, A \ominus(B+C)$ exist, then there exist $(A \ominus B) \ominus C$ and $(A \ominus B) \ominus C=A \ominus(B+C)$;

- If $A \ominus B, A \ominus C, C \ominus B$ exist, then there exist $(A \ominus B) \ominus(A \ominus C)$ and $(A \ominus B) \ominus(A \ominus C)=C \ominus B$.

Definition 2.1 We say that the interval-valued mapping $X:[a, b] \subset \mathbb{R}^{+} \rightarrow K_{C}(\mathbb{R})$ is continuous at the point $t \in[a, b]$ if for every $\varepsilon>0$ there exists $\delta=\delta(t, \varepsilon)>0$ such that

$$
H[X(t), X(s)] \leq \varepsilon
$$

for all $s \in[a, b]$ with $|t-s|<\delta$.

The strongly generalized differentiability was introduced in [26] and studied in $[6,24$, $25,31,41-43]$.

Definition 2.2 Let $X:(a, b) \rightarrow K_{C}(\mathbb{R})$ and $t \in(a, b)$. We say that $X$ is strongly generalized differentiable at $t$ if there exists $D_{H}^{g} X(t) \in K_{C}(\mathbb{R})$ such that 
(i) for all $h>0$ sufficiently small, $\exists X(t+h) \ominus X(t), \exists X(t) \ominus X(t-h)$ and

$$
\begin{aligned}
& \lim _{h \searrow 0} H\left[\frac{X(t+h) \ominus X(t)}{h}, D_{H}^{g} X(t)\right]=0, \\
& \lim _{h \searrow 0} H\left[\frac{X(t) \ominus X(t-h)}{h}, D_{H}^{g} X(t)\right]=0,
\end{aligned}
$$

or

(ii) for all $h>0$ sufficiently small, $\exists X(t) \ominus X(t+h), \exists X(t-h) \ominus X(t)$ and

$$
\begin{aligned}
& \lim _{h \searrow 0} H\left[\frac{X(t) \ominus X(t+h)}{-h}, D_{H}^{g} X(t)\right]=0, \\
& \lim _{h \backslash 0} H\left[\frac{X(t-h) \ominus X(t)}{-h}, D_{H}^{g} X(t)\right]=0,
\end{aligned}
$$

or

(iii) for all $h>0$ sufficiently small, $\exists X(t+h) \ominus X(t), \exists X(t-h) \ominus X(t)$ and

$$
\begin{aligned}
& \lim _{h \searrow 0} H\left[\frac{X(t+h) \ominus X(t)}{h}, D_{H}^{g} X(t)\right]=0, \\
& \lim _{h \backslash 0} H\left[\frac{X(t-h) \ominus X(t)}{-h}, D_{H}^{g} X(t)\right]=0,
\end{aligned}
$$

or

(iv) for all $h>0$ sufficiently small, $\exists X(t) \ominus X(t+h), \exists X(t) \ominus X(t-h)$ and the limits

$$
\begin{aligned}
& \lim _{h \searrow 0} H\left[\frac{X(t) \ominus X(t+h)}{-h}, D_{H}^{g} X(t)\right]=0, \\
& \lim _{h \searrow 0} H\left[\frac{X(t) \ominus X(t-h)}{h}, D_{H}^{g} X(t)\right]=0
\end{aligned}
$$

( $h$ at denominators means $\frac{1}{h}$ ).

In this definition, case (i) ((i)-differentiability for short) corresponds to the classical $\mathrm{H}$-derivative, so this differentiability concept is a generalization of the Hukuhara derivative. In this paper we consider only the two first of Definition 2.2. In the other cases, the derivative is trivial because it is reduced to a crisp element (more precisely, $D_{H}^{g} X(t) \in \mathbb{R}$ ). Further, we say that $X$ is (i)-differentiable or (ii)-differentiable on $[a, b]$, if it is differentiable in the sense (i) or (ii) of Definition 2.2, respectively.

Theorem 2.1 Let $X:(a, b) \rightarrow K_{C}(\mathbb{R})$ be (i)-differentiable or (ii)-differentiable on $(a, b)$, and assume that the derivative $D_{H}^{g} X$ is integrable over $(a, b)$. We have

(a) if $X$ is (i)-differentiable on $(a, b)$, then $\int_{a}^{b} D_{H}^{g} X(t) d t=X(b) \ominus X(a)$;

(b) if $X$ is (ii)-differentiable on $(a, b)$, then $\int_{a}^{b} D_{H}^{g} X(t) d t=(-1)(X(a) \ominus X(b))$.

Provided that, the above Hukuhara differences exist.

Lemma 2.1 (see [24-26]) Assume that $F:\left[t_{0}, t_{0}+p\right] \times K_{C}(\mathbb{R}) \rightarrow K_{C}(\mathbb{R})$ is continuous. The interval-valued differential equation (1.1) is equivalent to one of the following integral equations:

$$
X(t)=X\left(t_{0}\right)+\int_{t_{0}}^{t} F(s, X(s)) d s, \quad \forall t \in\left[t_{0}, t_{0}+p\right],
$$


if $X$ is (i)-differentiable, and

$$
X(t)=X\left(t_{0}\right) \ominus(-1) \int_{t_{0}}^{t} F(s, X(s)) d s, \quad \forall t \in\left[t_{0}, t_{0}+p\right]
$$

if $X$ is (ii)-differentiable, provided that the H-difference exists.

The following well-known result is useful in the next section.

Lemma 2.2 Let $a(t), b(t)$ and $c(t)$ be real-valued nonnegative continuous functions defined on $\mathbb{R}_{+}, d \geq 0$ is a constant for which the inequality

$$
a(t) \leq d+\int_{0}^{t}\left[b(s) a(s)+b(s) \int_{0}^{s} c(r) a(r) d r\right] d s
$$

holds for all $t \in \mathbb{R}_{+}$. Then

$$
a(t) \leq d\left[1+\int_{0}^{t} b(s) \exp \left(\int_{0}^{s}(b(r)+c(r)) d r\right) d s\right] .
$$

Corollary 2.1 (see [24-26]) Let $X:\left[t_{0}, t_{0}+p\right] \rightarrow K_{C}(\mathbb{R})$ be given. Denote $X(t)=[\underline{X}(t), \bar{X}(t)]$ for $t \in\left[t_{0}, t_{0}+p\right]$, where $\underline{X}, \bar{X}:\left[t_{0}, t_{0}+p\right] \rightarrow \mathbb{R}$.

(i) If the mapping $X$ is (i)-differentiable (i.e., classical Hukuhara differentiable) at $t \in\left[t_{0}, t_{0}+p\right]$, then the real-valued functions $\underline{X}, \bar{X}$ are differentiable at $t$ and $D_{H}^{g} X(t)=\left[\underline{X}^{\prime}(t), \bar{X}^{\prime}(t)\right]$.

(ii) If the mapping $X$ is (ii)-differentiable at $t \in\left[t_{0}, t_{0}+p\right]$, then the real-valued functions $\underline{X}, \bar{X}$ are differentiable at $t$ and $D_{H}^{g} X(t)=\left[\bar{X}^{\prime}(t), \underline{X}^{\prime}(t)\right]$.

\section{Main results}

For a positive number $\sigma$, we denote by $C_{\sigma}=C\left([-\sigma, 0], K_{C}(\mathbb{R})\right)$ the space of continuous mappings from $[-\sigma, 0]$ to $K_{C}(\mathbb{R})$. Define a metric $H_{\sigma}$ in $C_{\sigma}$ by

$$
H_{\sigma}[X, Y]=\sup _{t \in[-\sigma, 0]} H[X(t), Y(t)]
$$

Let $p>0$. Denote $I=\left[t_{0}, t_{0}+p\right], J=\left[t_{0}-\sigma, t_{0}\right] \cup I=\left[t_{0}-\sigma, t_{0}+p\right]$. For any $t \in I$, denote $X_{t}$ by the element of $C_{\sigma}$ defined by $X_{t}(s)=X(t+s)$ for $s \in[-\sigma, 0]$.

Let us consider the interval-valued functional integro-differential equations (IFIDEs) with the generalized Hukuhara derivative under the form

$$
\left\{\begin{array}{l}
D_{H}^{g} X(t)=F\left(t, X_{t}\right)+\int_{t_{0}}^{t} G\left(t, s, X_{s}\right) d s, \quad t \geq t_{0} \\
X(t)=\varphi\left(t-t_{0}\right)=\varphi_{0}, \quad t_{0} \geq t \geq t_{0}-\sigma
\end{array}\right.
$$

where $F: I \times C_{\sigma} \rightarrow K_{C}(\mathbb{R}), G: I \times I \times C_{\sigma} \rightarrow K_{C}(\mathbb{R}), \varphi \in C_{\sigma}$ and the symbol $D_{H}^{g}$ denotes the generalized Hukuhara derivative from Definition 2.2. By a solution to equation (3.1) we mean an interval-valued mapping $X \in C\left(J, K_{C}(\mathbb{R})\right)$ that satisfies $X(t)=\varphi\left(t-t_{0}\right)$ for $t \in\left[t_{0}-\sigma, t_{0}\right], X$ is differentiable on $\left[t_{0}, t_{0}+p\right]$ and $D_{H}^{g} X(t)=F\left(t, X_{t}\right)+\int_{t_{0}}^{t} G\left(t, s, X_{s}\right) d s$ for $t \in I$. We note that the solution in this sense is considered just one-side differentiable at $t=t_{0}$ (specifically, right-differentiable at $t=t_{0}$ ). 
Lemma 3.1 Assume that $F \in C\left(I \times C_{\sigma}, K_{C}(\mathbb{R})\right), G \in C\left(I \times I \times C_{\sigma}, K_{C}(\mathbb{R})\right)$ and $X \in$ $C\left(J, K_{C}(\mathbb{R})\right)$. Then the interval-valued mapping $t \rightarrow F\left(t, X_{t}\right)+\int_{t_{0}}^{t} G\left(t, s, X_{s}\right) d s$ belongs to $C\left(I, K_{C}(\mathbb{R})\right)$.

Remark 3.1 Under assumptions of the lemma above, the mapping $t \rightarrow F\left(t, X_{t}\right)+\int_{t_{0}}^{t} G(t, s$, $\left.X_{s}\right) d s$ is integrable over the interval $I$.

Remark 3.2 If $F: I \times C_{\sigma} \rightarrow K_{C}(\mathbb{R}), G: I \times I \times C_{\sigma} \rightarrow K_{C}(\mathbb{R})$ are continuous and $X \in$ $C\left(J, K_{C}(\mathbb{R})\right)$, then the mapping $t \rightarrow F\left(t, X_{t}\right)+\int_{t_{0}}^{t} G\left(t, s, X_{s}\right) d s$ is bounded on $I$. Also, the function $t \rightarrow F(t, 0)+\int_{t_{0}}^{t} G(t, s, 0) d s$ is bounded on $I$.

Lemma 3.2 Assume that $F: I \times C_{\sigma} \rightarrow K_{C}(\mathbb{R}), G: I \times I \times C_{\sigma} \rightarrow K_{C}(\mathbb{R})$ are continuous. An interval-valued mapping $X: J \rightarrow K_{C}(\mathbb{R})$ is called a local solution to problem (3.1) on $J$ if and only if $X$ is a continuous interval-valued mapping and it satisfies one of the following interval-valued integral equations:

$$
\left\{\begin{array}{l}
X(t)=\varphi\left(t-t_{0}\right) \quad \text { for } t \in\left[t_{0}-\sigma, t_{0}\right] \\
X(t)=\varphi(0)+\int_{t_{0}}^{t}\left(F\left(s, X_{s}\right)+\int_{t_{0}}^{t} G\left(t, s, X_{s}\right) d s\right) d s, \quad t \in I
\end{array}\right.
$$

if $X$ is (i)-differentiable,

$$
\left\{\begin{array}{l}
X(t)=\varphi\left(t-t_{0}\right) \quad \text { for } t \in\left[t_{0}-\sigma, t_{0}\right], \\
X(t)=\varphi(0) \ominus(-1) \int_{t_{0}}^{t}\left(F\left(s, X_{s}\right)+\int_{t_{0}}^{t} G\left(t, s, X_{s}\right) d s\right) d s, \quad t \in I,
\end{array}\right.
$$

if $X$ is (ii)-differentiable. We remark that in (3.3), the following statement is hidden: there exists the Hukuhara difference $\varphi(0) \ominus(-1) \int_{t_{0}}^{t}\left(F\left(s, X_{s}\right)+\int_{t_{0}}^{t} G\left(t, s, X_{s}\right) d s\right) d s$.

Proof We prove the case of (ii)-differentiability, the proof of the other case being similar. Assume that $X:\left[t_{0}, t_{0}+p\right] \rightarrow K_{C}(\mathbb{R})$ is a solution to problem (3.1). Hence $X$ is (ii)-differentiable on $\left[t_{0}, t_{0}+p\right]$ and $D_{H}^{g} X$ is integrable as a continuous function. Applying Theorem 2.1, we obtain that

$$
X\left(t_{0}\right)=X(t)+(-1) \int_{t_{0}}^{t} D_{H}^{g} X(s) d s
$$

for every $t \in\left[t_{0}, t_{0} p\right]$. Since $X\left(t_{0}\right)=\varphi(0)$ and $D_{H}^{g} X(s)=F\left(s, X_{s}\right)+\int_{t_{0}}^{s} G\left(s, \tau, X_{\tau}\right) d \tau$ for $s \in$ $\left[t_{0}, t_{0}+p\right]$, we easily obtain

$$
\left\{\begin{array}{l}
X(t)=\varphi\left(t-t_{0}\right) \quad \text { for } t \in\left[t_{0}-\sigma, t_{0}\right], \\
X(t)=\varphi(0) \ominus(-1) \int_{t_{0}}^{t}\left(F\left(s, X_{s}\right)+\int_{t_{0}}^{t} G\left(t, s, X_{s}\right) d s\right) d s, \quad t \in I .
\end{array}\right.
$$

To show that the opposite implication is true, let us assume that $X:\left[t_{0}, t_{0}+p\right] \rightarrow K_{C}(\mathbb{R})$ is a continuous interval-valued mapping and it satisfies equation (3.3). Equation (3.3) allows us to claim that $\varphi(0)=X\left(t_{0}\right)$ and that there exists the Hukuhara difference

$$
\varphi(0) \ominus(-1) \int_{t_{0}}^{t}\left(F\left(s, X_{s}\right)+\int_{t_{0}}^{t} G\left(t, s, X_{s}\right) d s\right) d s \quad \text { for every } t \in\left[t_{0}, t_{0}+p\right] .
$$


Now, let $t \in\left[t_{0}, t_{0}+p\right)$ and $h$ be such that $t+h \in\left[t_{0}, t_{0}+p\right]$. We observe that

$$
X(t) \ominus X(t+h)=(-1) \int_{t}^{t+h}\left(F\left(s, X_{s}\right)+\int_{t_{0}}^{s} G\left(s, \tau, X_{\tau}\right) d \tau\right) d s
$$

Indeed, we have by direct computation

$$
\begin{aligned}
X(t+h)+(-1) \int_{t}^{t+h}\left(F\left(s, X_{s}\right)+\int_{t_{0}}^{s} G\left(s, \tau, X_{\tau}\right) d \tau\right) d s \\
=\varphi(0) \ominus(-1) \int_{t_{0}}^{t+h}\left(F\left(s, X_{s}\right)+\int_{t_{0}}^{s} G\left(s, \tau, X_{\tau}\right) d \tau\right) d s \\
+(-1) \int_{t}^{t+h}\left(F\left(s, X_{s}\right)+\int_{t_{0}}^{s} G\left(s, \tau, X_{\tau}\right) d \tau\right) d s \\
=\varphi(0) \ominus(-1) \int_{t_{0}}^{t+h}\left(F\left(s, X_{s}\right)+\int_{t_{0}}^{s} G\left(s, \tau, X_{\tau}\right) d \tau\right) d s \\
+(-1) \int_{t_{0}}^{t+h}\left(F\left(s, X_{s}\right)+\int_{t_{0}}^{s} G\left(s, \tau, X_{\tau}\right) d \tau\right) d s \\
\quad \ominus(-1) \int_{t_{0}}^{t}\left(F\left(s, X_{s}\right)+\int_{t_{0}}^{s} G\left(s, \tau, X_{\tau}\right) d \tau\right) d s \\
=\varphi(0) \ominus(-1) \int_{t_{0}}^{t}\left(F\left(s, X_{s}\right)+\int_{t_{0}}^{s} G\left(s, \tau, X_{\tau}\right) d \tau\right) d s \\
=X(t) .
\end{aligned}
$$

Similarly to (3.4), we can obtain

$$
X(t-h) \ominus X(t)=(-1) \int_{t-h}^{t}\left(F\left(s, X_{s}\right)+\int_{t_{0}}^{s} G\left(s, \tau, X_{\tau}\right) d \tau\right) d s
$$

for $t \in\left(t_{0}, t_{0}+p\right]$. Multiplying (3.4)-(3.5) by $\frac{1}{-h}$ and passing to limit with $h \searrow 0$, we have by Definition 2.2 that $X$ is (ii)-differentiable, and consequently

$$
D_{H}^{g} X(t)=F\left(t, X_{t}\right)+\int_{t_{0}}^{t} G\left(t, s, X_{s}\right) d s \quad \text { for } t \in\left[t_{0}, t_{0}+p\right]
$$

Indeed, we have, for every $t \in\left[t_{0}, t_{0}+p\right]$,

$$
\lim _{h \rightarrow 0^{+}} \frac{X(t) \ominus X(t+h)}{-h}=\lim _{h \rightarrow 0^{+}} \frac{1}{h} \int_{t}^{t+h}\left(F\left(s, X_{s}\right)+\int_{t_{0}}^{s} G\left(s, \tau, X_{\tau}\right) d \tau\right) d s
$$

and

$$
\lim _{h \rightarrow 0^{+}} \frac{X(t-h) \ominus X(t)}{-h}=\lim _{h \rightarrow 0^{+}} \frac{1}{h} \int_{t-h}^{t}\left(F\left(s, X_{s}\right)+\int_{t_{0}}^{s} G\left(s, \tau, X_{\tau}\right) d \tau\right) d s .
$$

Since $F, G$ are continuous, for $h \rightarrow 0^{+}$, we obtain

$$
\lim _{h \rightarrow 0^{+}} \frac{X(t) \ominus X(t+h)}{-h}=F\left(t, X_{t}\right)+\int_{t_{0}}^{t} G\left(t, s, X_{s}\right) d s
$$


Proceeding as above, we can obtain

$$
\lim _{h \rightarrow 0^{+}} \frac{X(t-h) \ominus X(t)}{-h}=F\left(t, X_{t}\right)+\int_{t_{0}}^{t} G\left(t, s, X_{s}\right) d s .
$$

The proof is complete.

Definition 3.1 Let $X: J \rightarrow K_{C}(\mathbb{R})$ be an interval-valued function which is (i)-differentiable. If $X$ and its derivative satisfy problem (3.1), we say that $X$ is (i)-solution of problem (3.1). (i)-solution $X: J \rightarrow K_{C}(\mathbb{R})$ is unique if it holds $H[X(t), Y(t)]=0$ for any $Y: J \rightarrow K_{C}(\mathbb{R})$ which is (i)-solution of (3.1).

Definition 3.2 Let $X: J \rightarrow K_{C}(\mathbb{R})$ be an interval-valued function which is (ii)-differentiable. If $X$ and its derivative satisfy problem (3.1), we say that $X$ is (ii)-solution of problem (3.1). (ii)-solution $X: J \rightarrow K_{C}(\mathbb{R})$ is unique if it holds $H[X(t), Y(t)]=0$ for any $X: J \rightarrow K_{C}(\mathbb{R})$ which is (ii)-solution of (3.1).

Theorem 3.1 Let $\varphi\left(t-t_{0}\right) \in C_{\sigma}$ and suppose that $F \in C\left(I \times C_{\sigma}, K_{C}(\mathbb{R})\right), G \in C(I \times I \times$ $\left.C_{\sigma}, K_{C}(\mathbb{R})\right)$ satisfy the conditions: there exists a constant $L>0$ such that

$$
\max \{H[F(t, X), F(t, Y)], H[G(t, s, X), G(t, s, Y)]\} \leq L H_{\sigma}[X, Y]
$$

for every $t \in\left[t_{0}, t_{0}+p\right],(t, s) \in\left[t_{0}, t_{0}+p\right] \times\left[t_{0}, t_{0}+p\right]$ and $X, Y \in C_{\sigma}$. Moreover, there exists $M>0$ such that $\max \{H[F(t, X), 0], H[G(t, s, X), 0]\} \leq M$. Then the following successive approximations given by

$$
\begin{aligned}
& \widehat{X}^{0}(t)= \begin{cases}\varphi\left(t-t_{0}\right), & t \in\left[t_{0}-\sigma, t_{0}\right], \\
\varphi(0), & t \in I,\end{cases} \\
& \widehat{X}^{n+1}(t)= \begin{cases}\varphi\left(t-t_{0}\right), & t \in\left[t_{0}-\sigma, t_{0}\right], \\
\varphi(0)+\int_{t_{0}}^{t}\left(F\left(s, \widehat{X}_{s}^{n}\right)+\int_{t_{0}}^{s} G\left(s, \tau, \widehat{X}_{\tau}^{n}\right) d \tau\right) d s\end{cases}
\end{aligned}
$$

for the case of (i)-differentiability, and

$$
\begin{aligned}
& \widetilde{X}^{0}(t)= \begin{cases}\varphi\left(t-t_{0}\right), & t \in\left[t_{0}-\sigma, t_{0}\right], \\
\varphi(0), & t \in\left[t_{0}, t_{0}+d\right],\end{cases} \\
& \tilde{X}^{n+1}(t)= \begin{cases}\varphi\left(t-t_{0}\right), & t \in\left[t_{0}-\sigma, t_{0}\right], \\
\varphi(0) \ominus(-1) \int_{t_{0}}^{t}\left(F\left(s, \widetilde{X}_{s}^{n}\right)+\int_{t_{0}}^{s} G\left(s, \tau, \tilde{X}_{\tau}^{n}\right) d \tau\right) d s\end{cases}
\end{aligned}
$$

for the case of (ii)-differentiability (where $0<d \leq p$ such that equation (3.7) is well defined, i.e., the foregoing Hukuhara differences do exist), converge uniformly to two unique solutions $\widehat{X}(t)$ and $\widetilde{X}(t)$ of (3.1), respectively, on $[a, a+r]$ where $r=\min \{p, d\}$.

Proof We prove that for the case of (ii)-differentiability, the proof of the other case is similar. From assumptions of the theorem, we have

$$
\begin{aligned}
H & {\left[\widetilde{X}^{1}(t), \widetilde{X}^{0}(t)\right] } \\
& =H\left[\varphi(0) \ominus(-1) \int_{t_{0}}^{t}\left(F\left(s, \widetilde{X}_{s}^{0}\right)+\int_{t_{0}}^{s} G\left(s, \tau, \widetilde{X}_{\tau}^{0}\right) d \tau\right) d s, \varphi(0)\right]
\end{aligned}
$$




$$
\begin{aligned}
& \leq \int_{t_{0}}^{t}\left(H\left[F\left(s, \widetilde{X}_{s}^{0}\right), 0\right]+\int_{t_{0}}^{s} H\left[G\left(s, \tau, \widetilde{X}_{\tau}^{0}\right), 0\right] d \tau\right) d s \\
& \leq M\left(t-t_{0}\right)+M \frac{\left(t-t_{0}\right)^{2}}{2 !}
\end{aligned}
$$

for $t \in\left[t_{0}, t_{0}+r\right]$. Further, for every $n \geq 2$ and $t \in\left[t_{0}, t_{0}+r\right]$, we get

$$
\begin{aligned}
H & {\left[\widetilde{X}^{n+1}(t), \widetilde{X}^{n}(t)\right] } \\
= & H\left[\int_{t_{0}}^{t}\left(F\left(s, \widetilde{X}_{s}^{n}\right)+\int_{t_{0}}^{s} G\left(s, \tau, \widetilde{X}_{\tau}^{n}\right) d \tau\right) d s\right. \\
& \left.\int_{t_{0}}^{t}\left(F\left(s, \widetilde{X}_{s}^{n-1}\right)+\int_{t_{0}}^{s} G\left(s, \tau, \widetilde{X}_{\tau}^{n-1}\right) d \tau\right) d s\right] \\
\leq & L \int_{t_{0}}^{t}\left(H_{\sigma}\left[\widetilde{X}_{s}^{n}, \widetilde{X}_{s}^{n-1}\right]+\int_{t_{0}}^{s} H_{\sigma}\left[\widetilde{X}_{\tau}^{n}, \widetilde{X}_{\tau}^{n-1}\right] d \tau\right) d s \\
\leq & L \int_{t_{0}}^{t}\left(\sup _{\theta \in[-\sigma, 0]} H\left[\widetilde{X}^{n}(s+\theta), \widetilde{X}^{n-1}(s+\theta)\right]\right. \\
& \left.+\int_{t_{0}}^{s} \sup _{\theta \in[-\sigma, 0]} H\left[\widetilde{X}^{n}(\tau+\theta), \widetilde{X}^{n-1}(\tau+\theta)\right] d \tau\right) d s \\
= & L \int_{t_{0}}^{t}\left(\sup _{r \in[s-\sigma, s]} H\left[\widetilde{X}^{n}(r), \widetilde{X}^{n-1}(r)\right]+\int_{t_{0}}^{s} \sup _{v \in[\tau-\sigma, \tau]} H\left[\widetilde{X}^{n}(v), \widetilde{X}^{n-1}(v)\right] d v\right) d r .
\end{aligned}
$$

In particular, from (3.7) it follows that

$$
H\left[\widetilde{X}^{2}(t), \widetilde{X}^{1}(t)\right] \leq L M\left(\frac{\left(t-t_{0}\right)^{2}}{2 !}+2 \frac{\left(t-t_{0}\right)^{3}}{3 !}+\frac{\left(t-t_{0}\right)^{4}}{4 !}\right) .
$$

Therefore, by mathematical induction, for every $n \in \mathbb{N}$ and $t \in\left[t_{0}, t_{0}+r\right]$,

$$
\begin{aligned}
H & {\left[\widetilde{X}^{n+1}(t), \widetilde{X}^{n}(t)\right] } \\
& \leq M L^{n}\left(\frac{\left(t-t_{0}\right)^{n+1}}{(n+1) !}+{ }^{n} \lambda_{1} \frac{\left(t-t_{0}\right)^{n+2}}{(n+2) !}+\cdots+{ }^{n} \lambda_{n} \frac{\left(t-t_{0}\right)^{2 n+1}}{(2 n+1) !}+\frac{\left(t-t_{0}\right)^{2 n+2}}{(2 n+2) !}\right) .
\end{aligned}
$$

In inequality (3.8), $\lambda_{1}, \ldots, \lambda_{n}$ are balancing constants. We observe that for every $n \in$ $\{0,1,2, \ldots\}$, the function $\widetilde{X}^{n}(\cdot):\left[t_{0}-\sigma, t_{0}+r\right] \rightarrow K_{C}(\mathbb{R})$ is continuous. Indeed, since $\varphi \in C_{\sigma}$, $\tilde{X}^{0}(t)$ is continuous on $t \in\left[t_{0}-\sigma, t_{0}\right]$. We see that

$$
\begin{aligned}
H\left[\widetilde{X}^{1}(t+h), \widetilde{X}^{1}(t)\right]= & H\left[\varphi(0) \ominus(-1) \int_{t_{0}}^{t+h}\left(F\left(s, \widetilde{X}_{s}^{0}\right)+\int_{t_{0}}^{s} G\left(s, \tau, \widetilde{X}_{\tau}^{0}\right) d \tau\right) d s\right. \\
& \left.\varphi(0) \ominus(-1) \int_{t_{0}}^{t}\left(F\left(s, \widetilde{X}_{s}^{0}\right)+\int_{t_{0}}^{s} G\left(s, \tau, \widetilde{X}_{\tau}^{0}\right) d \tau\right) d s\right] \\
\leq & \int_{t}^{t+h}\left(H\left[F\left(s, \widetilde{X}_{s}^{0}\right), 0\right]+\int_{t_{0}}^{s} H\left[G\left(s, \tau, \widetilde{X}_{\tau}^{0}\right), 0\right] d \tau\right) d s \\
\leq & M h+\frac{M h^{2}}{2 !} \rightarrow 0 \quad \text { as } h \rightarrow 0^{+} .
\end{aligned}
$$


Thus, by mathematical induction, for every $n \geq 2$, we deduce that

$$
H\left[\tilde{X}^{n}(t+h), \tilde{X}^{n}(t)\right] \rightarrow 0
$$

as $h \rightarrow 0^{+}$. A similar inequality is obtained for $H\left[\widetilde{X}^{n}(t-h), \widetilde{X}^{n}(t)\right] \rightarrow 0$ as $h \rightarrow 0^{+}$. In the sequel, we shall show that for $\left\{\tilde{X}^{n}(t)\right\}$ the Cauchy convergence condition is satisfied uniformly in $t$, and as a consequence $\left\{\widetilde{X}^{n}(\cdot)\right\}$ is uniformly convergent. For $n>m>0$, from (3.8) we obtain

$$
\begin{aligned}
& \sup _{t \in I} H\left[\widetilde{X}^{n}(t), \widetilde{X}^{m}(t)\right] \\
& \quad=\sup _{t \in J} H\left[\widetilde{X}^{n}(t), \widetilde{X}^{m}(t)\right] \leq \sum_{k=m}^{n-1} \sup _{t \in J} H\left[\widetilde{X}^{k+1}(t), \widetilde{X}^{k}(t)\right] \\
& \quad \leq M \sum_{k=m}^{n-1}\left(\frac{\left(t-t_{0}\right)^{k+1}}{(k+1) !}+{ }^{k} \lambda_{1} \frac{\left(t-t_{0}\right)^{k+2}}{(k+2) !}+\cdots+{ }^{k} \lambda_{k} \frac{\left(t-t_{0}\right)^{2 k+1}}{(2 k+1) !}+\frac{\left(t-t_{0}\right)^{2 k+2}}{(2 k+2) !}\right) .
\end{aligned}
$$

The convergence of this series implies that for any $\varepsilon>0$ we find $n_{0} \in \mathbb{N}$ large enough such that for $n, m>n_{0}$,

$$
H\left[\tilde{X}^{n}(t), \tilde{X}^{m}(t)\right] \leq \varepsilon
$$

Since $\left(K_{C}(\mathbb{R}), H\right)$ is a complete metric space and (3.9) holds, the sequence $\left\{\tilde{X}^{n}(\cdot)\right\}$ is uniformly convergent to a mapping $\tilde{X} \in C\left(\left[t_{0}-\sigma, t_{0}+r\right], K_{C}(\mathbb{R})\right)$. We shall show that $\tilde{X}$ is (ii)-solution to (3.1). Since $\tilde{X}^{n}(t)=\varphi\left(t-t_{0}\right)$ for every $n=0,1,2, \ldots$ and every $t \in\left[t_{0}-\sigma, t_{0}\right]$, we easily have $\tilde{X}(t)=\varphi\left(t-t_{0}\right)$. For $s \in\left[t_{0}, t_{0}+r\right]$ and $n \in \mathbb{N}$,

$$
\begin{aligned}
& H\left[\int_{t_{0}}^{t} F\left(s, \widetilde{X}_{s}^{n}\right) d s, \int_{t_{0}}^{t} F\left(s, \tilde{X}_{s}\right) d s\right] \leq L \int_{t_{0}}^{t} \sup _{\theta \in[s-\sigma, s]} H\left[\tilde{X}^{n}(\theta), \widetilde{X}(\theta)\right] d \theta \rightarrow 0, \\
& H\left[\int_{t_{0}}^{t} \int_{t_{0}}^{s} G\left(s, \tau, \tilde{X}_{\tau}^{n}\right) d \tau d s, \int_{t_{0}}^{t} \int_{t_{0}}^{s} G\left(s, \tau, \widetilde{X}_{\tau}\right) d \tau d s\right] \\
& \quad \leq L \int_{t_{0}}^{t} \int_{t_{0}}^{s} \sup _{\theta \in[\tau-\sigma, \tau]} H\left[\tilde{X}^{n}(v), \widetilde{X}(v)\right] d v d s \rightarrow 0
\end{aligned}
$$

as $n \rightarrow \infty$ for any $t \in\left[t_{0}, t_{0}+r\right]$. Consequently, we have

$$
\begin{gathered}
H\left[\varphi(0), \widetilde{X}(t)+(-1) \int_{t_{0}}^{t}\left(F\left(s, \widetilde{X}_{s}\right)+\int_{t_{0}}^{t} G\left(t, s, \widetilde{X}_{s}\right) d s\right) d s\right] \\
\leq H\left[\widetilde{X}^{n}(t), \widetilde{X}(t)\right]+\int_{t_{0}}^{t}\left(H\left[F\left(s, \widetilde{X}_{s}^{n-1}\right), F\left(s, \widetilde{X}_{s}\right)\right]\right. \\
\left.\quad+\int_{t_{0}}^{s} H\left[G\left(s, \tau, \tilde{X}_{\tau}^{n-1}\right), G\left(s, \tau, \widetilde{X}_{\tau}\right)\right] d \tau\right) d s .
\end{gathered}
$$

We infer that

$$
H\left[\varphi(0), \tilde{X}(t)+(-1) \int_{t_{0}}^{t}\left(F\left(s, \widetilde{X}_{s}\right)+\int_{t_{0}}^{t} G\left(t, s, \widetilde{X}_{s}\right) d s\right) d s\right]=0
$$


for every $t \in\left[t_{0}, t_{0}+r\right]$. Therefore, $\widetilde{X}$ is the (ii)-solution of (3.1), due to Lemma 3.2 it follows that $\tilde{X}$ is the (ii)-solution of (3.1). For the uniqueness of the (ii)-solution $\widetilde{X}$, let us assume that $\tilde{X}, \tilde{Y} \in C\left(\left[t_{0}-\sigma, t_{0}+r\right], K_{C}(\mathbb{R})\right)$ are two solutions of (3.3). By definition of the solution, $\tilde{X}(t)=\tilde{Y}(t)$ if $t \in\left[t_{0}-\sigma, t_{0}\right]$. Note that for $t \in\left[t_{0}, t_{0}+r\right]$,

$$
\begin{aligned}
H & {[\tilde{X}(t), \widetilde{Y}(t)] } \\
& \leq L \int_{t_{0}}^{t}\left(\sup _{\theta \in[s-\sigma, s]} H[\tilde{X}(\theta), \widetilde{Y}(\theta)]+\int_{t_{0}}^{s} \sup _{v \in[\tau-\sigma, \tau]} H[\tilde{X}(v), \widetilde{Y}(v)] d \tau\right) d s .
\end{aligned}
$$

If we put $a(s)=\sup _{r \in[s-\sigma, s]} H[\widetilde{X}(r), \widetilde{Y}(r)], s \in\left[t_{0}, t\right] \subset\left[t_{0}, t_{0}+r\right]$, then we obtain

$$
a(t) \leq L \int_{t_{0}}^{t}\left(a(s)+\int_{t_{0}}^{s} a(\tau) d \tau\right) d s
$$

and by Lemma 2.2 we obtain that $a(t)=0$ on $\left[t_{0}, t_{0}+r\right]$. This proves the uniqueness of the (ii)-solution for (3.1)

Remark 3.3 The existence and uniqueness results for solutions of problem (3.1) can be obtained by using the contraction principle.

Now, we present the studies and results concerning the global existence and uniqueness of two solutions for (3.1), each one corresponding to a different type of differentiability, by using the contraction principle, which was studied in [5] for fuzzy functional differential equations. In the following, for a given $k>0$, we consider the set $S_{k}$ of all continuous interval-valued functions $X \in C\left(\left[t_{0}-\sigma, \infty\right), K_{C}(\mathbb{R})\right)$ such that $X(t)=\varphi\left(t-t_{0}\right)$ on $\left[t_{0}-\sigma, t_{0}\right]$ and $\sup _{t \geq t_{0}-\sigma}\{H[X(t), 0] \exp (-k t)\}<\infty$. On $S_{k}$ we can define the following metric:

$$
H_{k}[X, Y]=\sup _{t \geq t_{0}-\sigma}\{H[X(t), Y(t)] \exp (-k t)\}
$$

where $k>0$ is chosen suitably later. It is easy to prove that the space $\left(S_{k}, H_{k}\right)$ of continuous interval-valued functions $X:\left[t_{0}, \infty\right) \rightarrow K_{C}(\mathbb{R})$ is a complete metric space with distance (3.10).

Theorem 3.2 Assume that

(i) $F \in C\left(\left[t_{0}, \infty\right) \times C_{\sigma}, K_{C}(\mathbb{R})\right), G \in C\left(\left[t_{0}, \infty\right) \times\left[t_{0}, \infty\right) \times C_{\sigma}, K_{C}(\mathbb{R})\right)$ and there exists $a$ constant $L>0$ such that

$$
\max \{H[F(t, X), F(t, Y)], H[G(t, s, X), G(t, s, Y)]\} \leq L H_{\sigma}[X, Y]
$$

for all $X, Y \in C_{\sigma}$ and $t, s \geq t_{0}$;

(ii) there exist $M>0$ and $b>0$ such that

$$
\max \{H[F(t, 0), 0], H[G(t, s, 0), 0]\} \leq M \exp (b t)
$$

for all $t \geq t_{0}$, where $b<k$. 
Then

(a) the interval-valued functional integro-differential equation (3.1) has (i)-solution on $\left[t_{0}, \infty\right)$

(b) the interval-valued functional integro-differential equation (3.1) has (ii)-solution on $\left[t_{0}, \infty\right)$ if the following condition holds:

$$
\int_{t_{0}}^{t}\left(\operatorname{len}\left(F\left(s, X_{s}\right)\right)+\int_{t_{0}}^{t} \operatorname{len}\left(G\left(t, s, X_{s}\right)\right) d s\right) d s \leq \operatorname{len}(\varphi(0)), \quad t \geq t_{0} .
$$

Proof Since the way of the proof is similar for both cases, we only consider the case of (ii)-differentiability for $X$. Note that the space $\left(S_{k}, H_{k}\right)$ under inequality (3.11) depends on the positive constant $k$, the functions $F, G$ and the initial condition $\varphi \cdot \operatorname{In}\left(S_{k}, H_{k}\right)$, the continuity of $F, G$ guarantees that $S_{k}$ under inequality (3.11) is a closed set in $C\left(\left[t_{0}, \infty\right), K_{C}(\mathbb{R})\right)$, so that $S_{k}$ under inequality (3.11) is a complete metric space considering the distance $H_{k}$. We consider the complete metric space $\left(S_{k}, H_{k}\right)$ and define an operator

$$
\begin{aligned}
& \mathbb{T}: S_{k} \rightarrow S_{k}, \\
& X \rightarrow \mathbb{T} X
\end{aligned}
$$

given by

$$
(\mathbb{T} X)(t)= \begin{cases}\varphi\left(t-t_{0}\right) & \text { if } t \in\left[t_{0}-\sigma, t_{0}\right], \\ \varphi(0) \ominus(-1) \int_{t_{0}}^{t}\left(F\left(s, X_{s}\right)+\int_{t_{0}}^{s} G\left(s, \tau, X_{\tau}\right) d \tau\right) d s & \text { if } t \geq t_{0} .\end{cases}
$$

We can choose a big enough value for $k$ such that $\mathbb{T}$ is a contraction, so the Banach fixed point theorem provides the existence of a unique fixed point for $\mathbb{T}$, that is, a unique solution for (3.1).

First, we shall prove that $\mathbb{T}\left(S_{k}\right) \subseteq S_{k}$, i.e., the operator $T$ is well defined, with assumption $k>b$. Indeed, let $X \in S_{k}$. For each $t \geq t_{0}$, we get

$$
\begin{aligned}
& H_{k}[(\mathbb{T} X)(t), 0] \\
&=\sup _{t \geq t_{0}}\left\{H\left[\varphi(0) \ominus(-1) \int_{t_{0}}^{t}\left(F\left(s, X_{s}\right)+\int_{t_{0}}^{s} G\left(s, \tau, X_{\tau}\right) d \tau\right) d s, 0\right] \exp (-k t)\right\} \\
& \leq \sup _{t \geq t_{0}}\left\{\left(H[\varphi(0), 0]+\int_{t_{0}}^{t}\left\{H\left[F\left(s, X_{s}\right), F(s, 0)\right]+H[F(s, 0), 0]\right\} d s\right.\right. \\
&\left.\left.\quad+\int_{t_{0}}^{t}\left(\int_{t_{0}}^{s}\left\{H\left[G\left(s, \tau, X_{\tau}\right), G(s, \tau, 0)\right]+H[G(s, \tau, 0), 0]\right\} d \tau\right) d s\right) \exp (-k t)\right\} \\
& \leq \sup _{t \geq t_{0}}\left\{\left(H[\varphi(0), 0]+L \int_{t_{0}}^{t} H_{\sigma}\left[X_{s}, 0\right] d s+\frac{M}{b} \exp (b t)\right.\right. \\
&\left.\left.\quad+L \int_{t_{0}}^{t}\left(\int_{t_{0}}^{s} H_{\sigma}\left[X_{\tau}, 0\right] d \tau\right) d s+\frac{M}{b^{2}} \exp (b t)\right) \exp (-k t)\right\} \\
& \leq \sup _{t \geq t_{0}}\left\{\left(H[\varphi(0), 0]+L \int_{t_{0}}^{t} \sup _{\theta \in[-\sigma, 0]} H[X(s+\theta), 0] d s+\frac{M}{b} \exp (b t)\right.\right. \\
&\left.\left.\quad+L \int_{t_{0}}^{t}\left(\int_{t_{0}}^{s} \sup _{\theta \in[-\sigma, 0]} H[X(\tau+\theta), 0] d \tau\right) d s+\frac{M}{b^{2}} \exp (b t)\right) \exp (-k t)\right\} .
\end{aligned}
$$


Since $X \in S_{k}$, there exists $\rho>0$ such that $H[X(t), 0]<\rho \exp (k t)$ for all $t \geq t_{0}-\sigma$. Therefore, for all $t \geq t_{0}$, we obtain

$$
\begin{aligned}
H_{k} & {[(\mathbb{T} X)(t), 0] } \\
& \leq \sup _{t \geq t_{0}}\left\{\left(H[\varphi(0), 0]+\left(1+\frac{1}{k}\right) \frac{\rho L}{k} \exp (k t)+\left(1+\frac{1}{b}\right) \frac{M}{b} \exp (b t)\right) \exp (-k t)\right\} \\
& \leq H[\varphi(0), 0]+\left(1+\frac{1}{b}\right) \frac{1}{b}(M+\rho L) \leq K+\left(1+\frac{1}{b}\right) \frac{1}{b}(M+\rho L)<\infty .
\end{aligned}
$$

We infer that $\mathbb{T} X \in S_{k}$.

Next, we shall prove that $\mathbb{T}$ is a contraction by metric $H_{k}$. Let $X, Y \in S_{k}$. Then, for $\theta \in$ $[-\sigma, 0], H\left[(\mathbb{T} X)\left(t_{0}+\theta\right),(\mathbb{T} Y)\left(t_{0}+\theta\right)\right]=0$. For each $t \geq t_{0}$, we have

$$
\begin{aligned}
H_{k} & {[(\mathbb{T} X)(t),(\mathbb{T} Y)(t)] } \\
= & \sup _{t \geq t_{0}}\{H[(\mathbb{T} X)(t),(\mathbb{T} Y)(t)] \exp (-k t)\} \\
= & \sup _{t \geq t_{0}}\left\{H \left[\varphi(0) \ominus(-1) \int_{t_{0}}^{t}\left(F\left(s, X_{s}\right)+\int_{t_{0}}^{s} G\left(s, \tau, X_{\tau}\right) d \tau\right) d s,\right.\right. \\
& \left.\left.\varphi(0) \ominus(-1) \int_{t_{0}}^{t}\left(F\left(s, Y_{s}\right)+\int_{t_{0}}^{s} G\left(s, \tau, Y_{\tau}\right) d \tau\right) d s\right] \exp (-k t)\right\} \\
\leq & \sup _{t \geq t_{0}}\left\{\left(L \int_{t_{0}}^{t}\left(H_{\sigma}\left[X_{s}, Y_{s}\right]+\int_{t_{0}}^{s} H_{\sigma}\left[X_{\tau}, Y_{\tau}\right] d \tau\right) d s\right) \exp (-k t)\right\} \\
= & \sup _{t \geq t_{0}}\left\{\left(L \int_{t_{0}}^{t} \sup _{\theta \in[-\sigma, 0]} H[X(s+\theta), Y(s+\theta)] d s\right.\right. \\
& \left.\left.+L \int_{t_{0}}^{t}\left(\int_{t_{0}}^{s} \sup _{\theta \in[-\sigma, 0]} H[X(\tau+\theta), Y(\tau+\theta)]\right) d s\right) \exp (-k t)\right\} \\
= & \sup _{t \geq t_{0}}\left\{\left(L \int_{t_{0}}^{t} \sup _{r \in[s-\sigma, s]} H[X(r), Y(r)] d r\right.\right. \\
& \left.\left.+L \int_{t_{0}}^{t}\left(\int_{t_{0}}^{s} \sup _{v \in[\tau-\sigma, \tau]} H[X(v), Y(v)] d v\right) d s\right) \exp (-k t)\right\} \\
\leq & L H_{k}[X, Y] \sup _{t \geq t_{0}}\left(\int_{t_{0}}^{t}\left(\exp (k(r-t))+\int_{t_{0}}^{s} \exp (k(v-t)) d v\right) d r\right) \\
\leq & \frac{(1+k) L H_{k}[x, y]}{k^{2}} .
\end{aligned}
$$

Choosing $k>b$ and $\frac{(1+k) L}{k^{2}}<1$, it follows that the operator $\mathbb{T}$ on $S_{k}$ is a contraction. Using the Banach fixed point theorem provides the existence of a unique fixed point for $\mathbb{T}$, and the unique fixed point of $\mathbb{T}$ is in the space $S_{k}$, that is, a unique solution for (3.1) in the case of (ii)-differentiability.

\section{Illustrations}

In this part, some simple examples are given to illustrate the theory of IFIDEs. We shall consider IFIDEs (3.1) with (i) and (ii) derivatives, respectively. Let us start the illustrations 
with considering the following interval-valued functional integro-differential equation:

$$
\left\{\begin{array}{l}
D_{H}^{g} X(t)=F\left(t, X_{t}\right)+\int_{t_{0}}^{t} k(t, s) X_{s} d s, \quad t \in J, \\
X(t)=\varphi\left(t-t_{0}\right), \quad t \in\left[-\sigma, t_{0}\right],
\end{array}\right.
$$

where $F: I \times C_{\sigma} \rightarrow K_{C}(\mathbb{R}), k(t, s): I \times I \rightarrow \mathbb{R}$. Let $X(t)=[\underline{X}(t), \bar{X}(t)]$. By using Corollary 2.1, we have the following two cases.

If we consider the derivative of $X(t)$ by using (i)-differentiability, then from Corollary 2.1, we have $D_{H}^{g} X(t)=\left[\underline{X}^{\prime}(t), \bar{X}^{\prime}(t)\right]$ for $t \geq t_{0}$. Therefore, (4.1) is translated into the following delay integro-differential system:

$$
\begin{cases}\underline{X}^{\prime}(t)=\underline{F}\left(t, \underline{X}_{t}, \bar{X}_{t}\right)+\int_{t_{0}}^{t} \frac{k(t, s) X_{s}}{\bar{X}^{\prime}}(t)=\bar{F}\left(t, \underline{X}_{t}, \bar{X}_{t}\right)+\int_{t_{0}}^{t} \overline{\overline{k(t, s) X_{s}}} d s, \quad t \geq t_{0}, \\ \underline{X}(t)=\varphi\left(t-t_{0}\right), \quad \sigma \leq t \leq t_{0}, \\ \overline{\bar{X}}(t)=\bar{\varphi}\left(t-t_{0}\right), \quad \sigma \leq t \leq t_{0} .\end{cases}
$$

If we consider the derivative of $X(t)$ by using (ii)-differentiability, then from Corollary 2.1, we have $D_{H}^{g} X(t)=\left[\bar{X}^{\prime}(t), \underline{X}^{\prime}(t)\right]$ for $t \geq t_{0}$. Therefore, (4.1) is translated into the following delay integro-differential system:

$$
\begin{cases}\bar{X}^{\prime}(t)=\underline{F}\left(t, \underline{X}_{t}, \bar{X}_{t}\right)+\int_{t_{0}}^{t} \frac{k(t, s) X_{s}}{d} d s, & t \geq t_{0}, \\ \underline{X}^{\prime}(t)=\bar{F}\left(t, \underline{X}_{t}, \bar{X}_{t}\right)+\int_{t_{0}}^{t} \overline{k(t, s) X_{s}} d s, & t \geq t_{0}, \\ \underline{X}(t)=\varphi\left(t-t_{0}\right), \quad \sigma \leq t \leq t_{0}, & \\ \overline{\bar{X}}(t)=\bar{\varphi}\left(t-t_{0}\right), \quad \sigma \leq t \leq t_{0}, & \end{cases}
$$

where

$$
\begin{aligned}
& \underline{k(t, s) X_{s}}= \begin{cases}k(t, s) \underline{X}_{s}, & k(t, s) \geq 0, \\
k(t, s) \bar{X}_{s}, & k(t, s)<0,\end{cases} \\
& \overline{k(t, s) X_{s}}= \begin{cases}k(t, s) \bar{X}_{s}, & k(t, s) \geq 0, \\
k(t, s) \underline{X}_{s}, & k(t, s)<0 .\end{cases}
\end{aligned}
$$

Remark 4.1 If we ensure that the solutions $(\underline{X}(t), \bar{X}(t))$ of systems (4.2) and (4.3) respectively are valid sets of interval-valued functions and if the derivatives $\left(\underline{X}^{\prime}(t), \bar{X}^{\prime}(t)\right)$ are valid sets of interval-valued functions with two kinds of differentiability respectively, then we can construct the solution of interval-valued functional differential equation (4.1).

Next, we shall consider two examples being a simple illustration for the theory of interval-valued functional integro-differential equations.

Example 4.1 Let us consider the linear interval-valued functional integro-differential equation (with $k(t, s) \equiv 0$ ) under two kinds of Hukuhara derivatives

$$
\left\{\begin{array}{l}
D_{H}^{g} X(t)=-\lambda X\left(t-\frac{1}{2}\right) \\
X(t)=\varphi(t), \quad t \in\left[-\frac{1}{2}, 0\right]
\end{array}\right.
$$

where $\varphi(t)=[-1,1], \lambda>0$. In this example we shall solve $(4.4)$ on $[0,1]$. 
Figure 1 (i)-solution to $(4.4)(\lambda=0.5)$.

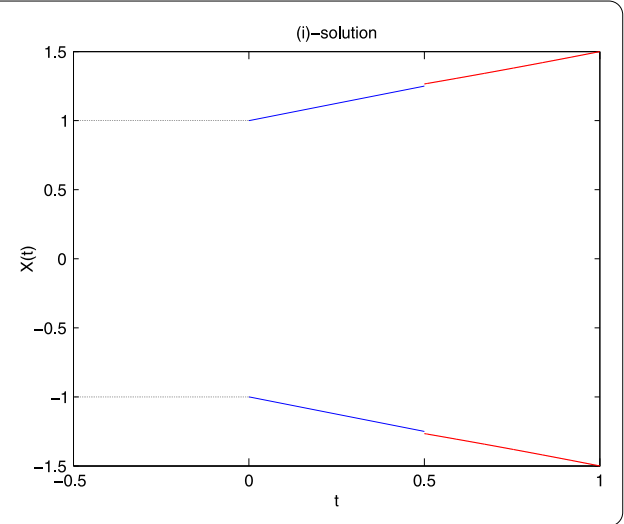

Case 1. Considering (i)-differentiability, problem (4.4) is translated into the following delay system:

$$
\left\{\begin{array}{l}
\underline{X}^{\prime}(t)=-\lambda \bar{X}\left(t-\frac{1}{2}\right), \quad t \geq 0, \\
\bar{X}^{\prime}(t)=-\lambda \underline{X}\left(t-\frac{1}{2}\right), \quad t \geq 0, \\
\underline{X}(t)=-1, \quad-\frac{1}{2} \leq t \leq 0 \\
\bar{X}(t)=1, \quad-\frac{1}{2} \leq t \leq 0
\end{array}\right.
$$

Solving delay system (4.5) by using the method of steps, we obtain a unique (i)-solution to (4.4) defined on $[0,1]$ and it is of the form

$$
X(t)= \begin{cases}{[-1(1+\lambda t),(1+\lambda t)]} & \text { for } t \in\left[0, \frac{1}{2}\right], \\ {\left[-1\left(1+\lambda t+\frac{\lambda^{2}(t-1)^{2}}{2}\right), 1+\lambda t+\frac{\lambda^{2}(t-1)^{2}}{2}\right]} & \text { for } t \in\left[\frac{1}{2}, 1\right] .\end{cases}
$$

The (i)-solution is illustrated in Figure 1.

Case 2. Considering (ii)-differentiability, problem (4.4) is translated into the following delay system:

$$
\left\{\begin{array}{l}
\bar{X}^{\prime}(t)=-\lambda \bar{X}\left(t-\frac{1}{2}\right), \quad t \geq 0, \\
\underline{X}^{\prime}(t)=-\lambda \underline{X}\left(t-\frac{1}{2}\right), \quad t \geq 0, \\
\underline{X}(t)=-1, \quad-\frac{1}{2} \leq t \leq 0, \\
\bar{X}(t)=1, \quad-\frac{1}{2} \leq t \leq 0 .
\end{array}\right.
$$

We obtain a unique (ii)-solution to (4.4) defined on $[0,1]$ and it is of the form

$$
X(t)= \begin{cases}{[\lambda t-1,1-\lambda t]} & \text { for } t \in\left[0, \frac{1}{2}\right], \\ {\left[-1\left(1-\lambda t+\frac{\lambda^{2}(t-1)^{2}}{2}\right), 1-\lambda t+\frac{\lambda^{2}(t-1)^{2}}{2}\right]} & \text { for } t \in\left[\frac{1}{2}, 1\right] .\end{cases}
$$

The (ii)-solution is illustrated in Figure 2.

Example 4.2 Let us consider the linear interval-valued functional integro-differential equation under two kinds of Hukuhara derivatives

$$
\left\{\begin{array}{l}
D_{H}^{g} X(t)=X\left(t-\frac{1}{2}\right)+\alpha \int_{t_{0}}^{t} e^{(s-t)} X\left(s-\frac{1}{2}\right) d s, \\
X(t)=\varphi(t), \quad t \in\left[-\frac{1}{2}, 0\right]
\end{array}\right.
$$

where $\varphi(t)=[1,2-t], \alpha \in \mathbb{R} \backslash\{0\}$. In this example we shall solve (4.7) on $[0,1 / 2]$. 
Figure 2 (ii)-solution to $(4.4)(\lambda=0.5)$.

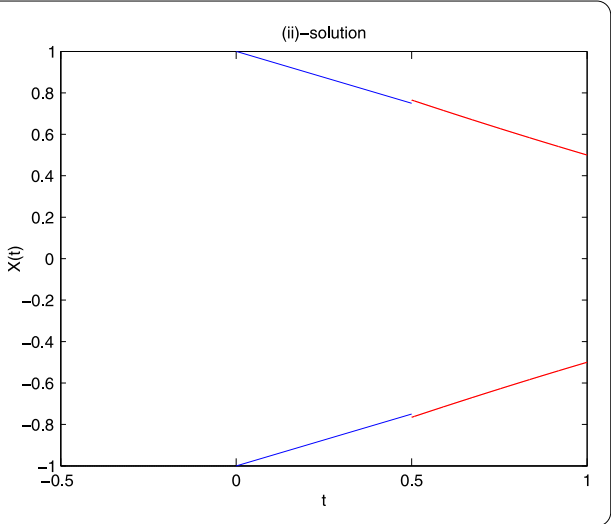

Case 1. $(\alpha>0)$ From (4.2), we get

$$
\begin{cases}\underline{X}^{\prime}(t)=\underline{X}\left(t-\frac{1}{2}\right)+\alpha \int_{0}^{t} e^{(s-t)} \underline{X}\left(s-\frac{1}{2}\right) d s, & t \geq 0 \\ \bar{X}^{\prime}(t)=\bar{X}\left(t-\frac{1}{2}\right)+\alpha \int_{0}^{t} e^{(s-t)} \bar{X}\left(s-\frac{1}{2}\right) d s, & t \geq 0 \\ \underline{X}(t)=1, \quad \frac{-1}{2} \leq t \leq 0 \\ \bar{X}(t)=2-t, \quad \frac{-1}{2} \leq t \leq 0\end{cases}
$$

Following the method of steps, we obtain the (i)-solution to (4.7) defined on $[0,1 / 2]$ and it is of the form

$$
X(t)=\left[1+\frac{t}{2}+\frac{\alpha}{2}\left(1-e^{-t}\right), 2+2 t-\frac{t^{2}}{2}+\alpha\left(3-t-3 e^{-t}\right)\right], \quad t \in[0,1 / 2] .
$$

From (4.3) we obtain

$$
\begin{cases}\bar{X}^{\prime}(t)=\underline{X}\left(t-\frac{1}{2}\right)+\alpha \int_{0}^{t} e^{(s-t)} \underline{X}\left(s-\frac{1}{2}\right) d s, & t \geq 0 \\ \underline{X}(t)=\bar{X}\left(t-\frac{1}{2}\right)+\alpha \int_{0}^{t} e^{(s-t)} \bar{X}\left(s-\frac{1}{2}\right) d s, & t \geq 0 \\ \underline{X}(t)=1, \quad \frac{-1}{2} \leq t \leq 0 & \\ \bar{X}(t)=2-t, \quad \frac{-1}{2} \leq t \leq 0\end{cases}
$$

The (ii)-solution to (4.7) defined on $[0,1 / 2]$ is of the form

$$
X(t)=\left[1+2 t-\frac{t^{2}}{2}+\alpha\left(3-t-3 e^{-t}\right), 2+\frac{\alpha}{2}\left(1-e^{-t}\right)\right], \quad t \in[0,1 / 2] .
$$

In Figures 3 and 4, (i)-solution and (ii)-solution curves of (4.7) are given.

Case 2. $(\alpha<0)$ From $(4.2)$ we get

$$
\begin{cases}\underline{X}^{\prime}(t)=\underline{X}\left(t-\frac{1}{2}\right)+\alpha \int_{0}^{t} e^{(s-t)} \bar{X}\left(s-\frac{1}{2}\right) d s, & t \geq 0 \\ \bar{X}^{\prime}(t)=\bar{X}\left(t-\frac{1}{2}\right)+\alpha \int_{0}^{t} e^{(s-t)} \underline{X}\left(s-\frac{1}{2}\right) d s, & t \geq 0 \\ \underline{X}(t)=1, \quad \frac{-1}{2} \leq t \leq 0 & \\ \bar{X}(t)=2-t, \quad \frac{-1}{2} \leq t \leq 0\end{cases}
$$

By solving delay integro-differential system (4.10), we obtain (i)-solution

$$
X(t)=\left[1+\frac{t}{2}+\alpha\left(3-t-3 e^{-t}\right), 2+2 t-\frac{t^{2}}{2}+\frac{\alpha}{2}\left(1-e^{-t}\right)\right], \quad t \in[0,1 / 2] .
$$

The (i)-solution of $(4.7)$ on $[-1 / 2,1 / 2]$ is illustrated in Figure 5. 
Figure 3 Graphs of $\underline{X}(t), \bar{X}(t)$ for $t \in\left[\frac{-1}{2}, \frac{1}{2}\right]$,

Figure 3
$\alpha=0.1$.

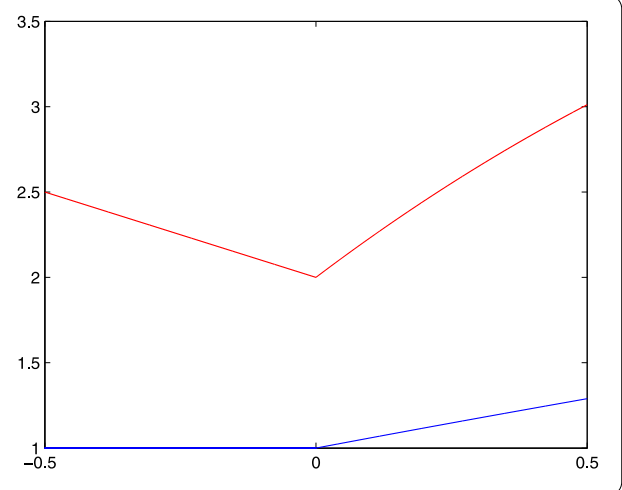

Figure 4 Graphs of $\underline{X}(t), \bar{X}(t)$ for $t \in\left[\frac{-1}{2}, \frac{1}{2}\right]$, $\alpha=0.1$.

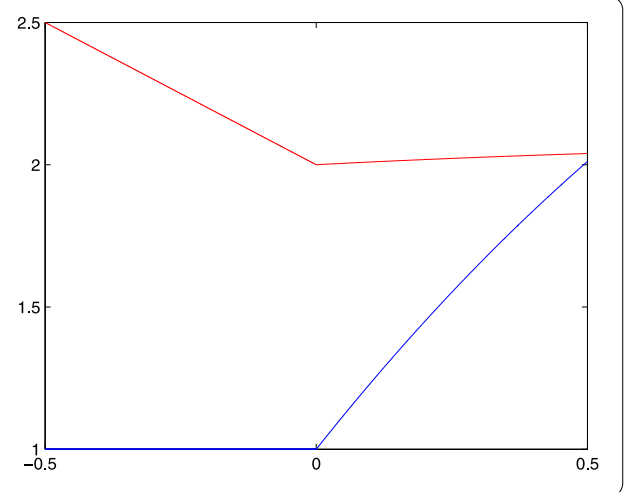

Figure 5 Graphs of $\underline{X}(t), \bar{X}(t)$ for $t \in\left[\frac{-1}{2}, \frac{1}{2}\right]$, $\alpha=-0.1$.

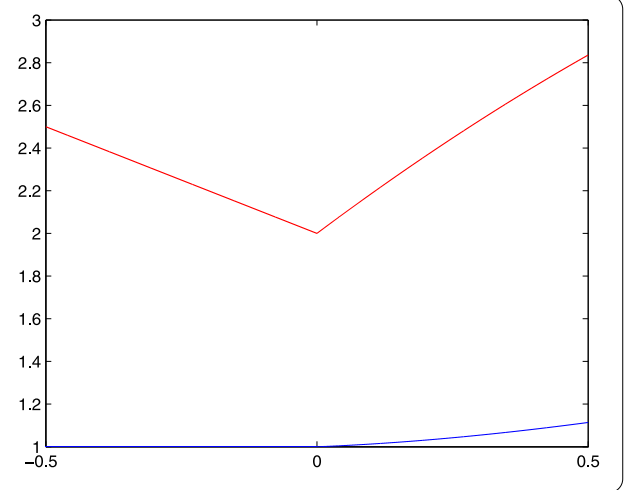

From (4.3) we obtain

$$
\begin{cases}\bar{X}^{\prime}(t)=\underline{X}\left(t-\frac{1}{2}\right)+\alpha \int_{0}^{t} e^{(s-t)} \bar{X}\left(s-\frac{1}{2}\right) d s, & t \geq 0 \\ \underline{X^{\prime}}(t)=\bar{X}\left(t-\frac{1}{2}\right)+\alpha \int_{0}^{t} e^{(s-t)} \underline{X}\left(s-\frac{1}{2}\right) d s, & t \geq 0 \\ \underline{X}(t)=1, \quad \frac{-1}{2} \leq t \leq 0 & \\ \bar{X}(t)=2-t, \quad \frac{-1}{2} \leq t \leq 0\end{cases}
$$

By solving delay integro-differential systems (4.11), we obtain (ii)-solution

$$
X(t)=\left[1+2 t-\frac{t^{2}}{2}+\frac{\alpha}{2}\left(1-e^{-t}\right), 2+\frac{t}{2}+\alpha\left(3-t-3 e^{-t}\right)\right], \quad t \in[0,1 / 2] .
$$

The (ii)-solution of $(4.7)$ on $[-1 / 2,1 / 2]$ is illustrated in Figure 6. 


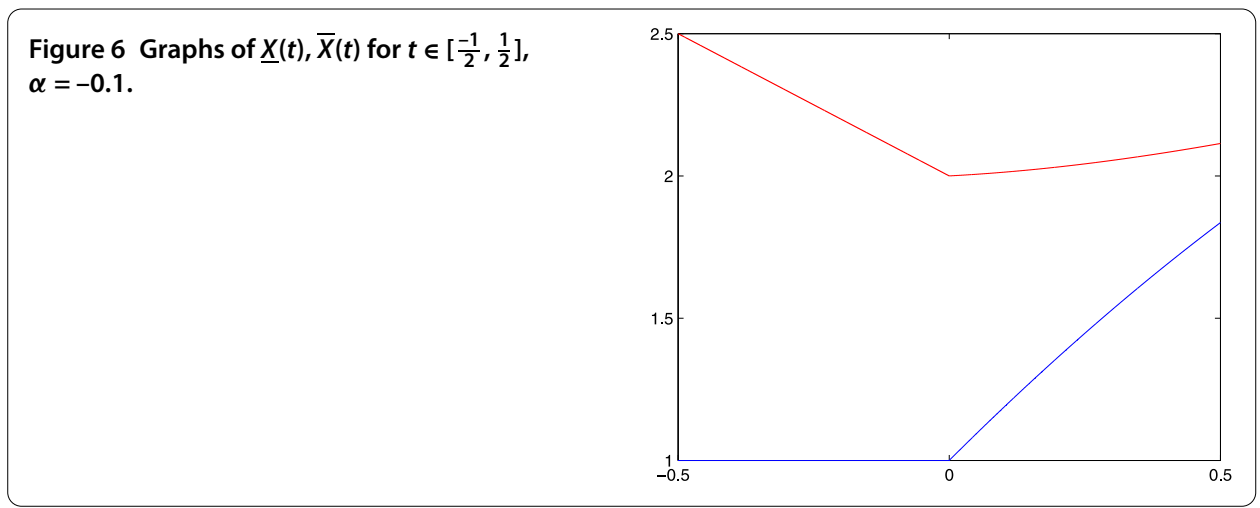

\section{Conclusion}

In this study, we have established the local and global existence and uniqueness results of two solutions for interval-valued functional integro-differential equations. For the local existence and uniqueness, we use the method of successive approximations under the Lipschitz condition, and for global existence and uniqueness, we use the contraction principle under suitable conditions. In our further work, we would like to use these results to study the local and global existence and uniqueness results of solutions for intervalvalued functional integro-differential equations under Caputo-type interval-valued fractional derivatives.

Competing interests

The authors declare that they have no competing interests.

\section{Authors' contributions}

All authors contributed equally to the writing of this paper. All authors read and approved the final version of the manuscript.

\section{Author details}

${ }^{1}$ Division of Computational Mathematics and Engineering, Institute for Computational Science, Ton Duc Thang University, Ho Chi Minh City, Vietnam. 2Faculty of Mathematics and Computer Science, University of Science, VNU, Ho Chi Minh City, Vietnam. ${ }^{3}$ Faculty of Natural Science and Technology, Tay Nguyen University, 567 Le Duan Road, Buon Ma Thuot City, Daklak Province, Vietnam.

\section{Acknowledgements}

The authors would like to express their gratitude to the anonymous referees for their helpful comments and suggestions, which have greatly improved the paper.

Received: 16 February 2014 Accepted: 28 June 2014 Published: 22 Jul 2014

\section{References}

1. Hale, JK: Theory of Functional Differential Equations. Springer, New York (1977)

2. Kolmanovskii, VB, Myshkis, A: Applied Theory of Functional Differential Equations. Kluwer Academic, Dordrecht (1992)

3. Kuang, Y: Delay Differential Equations with Applications in Population Dynamics. Academic Press, Boston (1993)

4. Lupulescu, V: On a class of functional differential equations in Banach spaces. Electron. J. Qual. Theory Differ. Equ. 2010, 64 (2010)

5. Lupulescu, V: On a class of fuzzy functional differential equations. Fuzzy Sets Syst. 160, 1547-1562 (2009)

6. Malinowski, MT: Second type Hukuhara differentiable solutions to the delay set-valued differential equations. Appl. Math. Comput. 218(18), 9427-9437 (2012)

7. De Blasi, FS, lervolino, F: Equazioni differenziali con soluzioni a valore compatto convesso. Boll. Unione Mat. Ital. 4(2), 491-501 (1969)

8. Agarwal, RP, O'Regan, D: Existence for set differential equations via multivalued operator equations. Differ. Equ. Appl. 5, 1-5 (2007)

9. Agarwal, RP, O'Regan, D, Lakshmikantham, V: Viability theory and fuzzy differential equations. Fuzzy Sets Syst. 151(3), 563-580 (2005)

10. Agarwal, RP, O'Regan, D, Lakshmikantham, V: A stacking theorem approach for fuzzy differential equations. Nonlinear Anal. TMA 55(3), 299-312 (2003)

11. Bhaskar, TG, Lakshmikantham, V: Set differential equations and flow invariance. J. Appl. Anal. 82(2), $357-368$ (2003) 
12. De Blasi, FS, Lakshmikantham, $\mathrm{V}$, Bhaskar, TG: An existence theorem for set differential inclusions in a semilinear metric space. Control Cybern. 36(3), 571-582 (2007)

13. Devi, JV: Generalized monotone iterative technique for set differential equations involving causal operators with memory. Int. J. Adv. Eng. Sci. Appl. Math. 8(3), 74-83 (2011)

14. Hoa, NV, Phu, ND: On maximal and minimal solutions for set-valued differential equations with feedback control. Abstr. Appl. Anal. 2012, Article ID 816218 (2012)

15. Kaleva, O: Fuzzy differential equations. Fuzzy Sets Syst. 24, 301-317 (1987)

16. Lakshmikantham, V, Bhaskar, TG, Devi, JV: Theory of Set Differential Equations in Metric Spaces. Cambridge Scientific Publishers, Cambridge (2006)

17. Lakshmikantham, V, Mohapatra, R: Theory of Fuzzy Differential Equations and Inclusions. Taylor \& Francis, London (2003)

18. Lakshmikantham, $V$, Tolstonogov, AA: Existence and interrelation between set and fuzzy differential equations. Nonlinear Anal. TMA 55(3), 255-268 (2003)

19. Phu, ND, Quang, LT, Tung, TT: Stability criteria for set control differential equations. Nonlinear Anal. TMA 69, 3715-3721 (2008)

20. Phu, ND, Tung, TT: Some results on sheaf-solutions of sheaf set control problems. Nonlinear Anal. TMA 67, 1309-1315 (2007)

21. Puri, M, Ralescu, D: Differentials of fuzzy functions. J. Math. Anal. Appl. 91, 552-558 (1983)

22. Song, S, Wu, C: Existence and uniqueness of solutions to Cauchy problem of fuzzy differential equations. Fuzzy Sets Syst. 110, 55-67 (2000)

23. Tu, NN, Tung, TT: Stability of set differential equations and applications. Nonlinear Anal. TMA 71, 1526-1533 (2009)

24. Malinowski, MT: Interval Cauchy problem with a second type Hukuhara derivative. Inf. Sci. 213, $94-105$ (2012)

25. Malinowski, MT: Interval differential equations with a second type Hukuhara derivative. Appl. Math. Lett. 24, 2118-2123 (2011)

26. Stefanini, L, Bede, B: Generalized Hukuhara differentiability of interval-valued functions and interval differential equations. Nonlinear Anal. TMA 71, 1311-1328 (2009)

27. Hukuhara, M: Intégration des applications mesurables dont la valeur est un compact convexe. Funkc. Ekvacioj 10, 205-229 (1967)

28. Agarwal, RP, Arshad, S, O'Regan, D, Lupulescu, V: A Schauder fixed point theorem in semilinear spaces and applications. Fixed Point Theory Appl. 2013, 306 (2013)

29. Chalco-Cano, Y, Rufián-Lizana, A, Román-Flores, H, Jiménez-Gamero, MD: Calculus for interval-valued functions using generalized Hukuhara derivative and applications. Fuzzy Sets Syst. 219, 49-67 (2013)

30. Khastan, A, Nieto, JJ, Rodríguez-López, R: Schauder fixed-point theorem in semilinear spaces and its application to fractional differential equations with uncertainty. Fixed Point Theory Appl. 2014, 21 (2014)

31. Malinowski, MT: On set differential equations in Banach spaces - a second type Hukuhara differentiability approach. Appl. Math. Comput. 219(1), 289-305 (2012)

32. Moore, R, Lodwick, W: Interval analysis and fuzzy set theory. Fuzzy Sets Syst. 135(1), 5-9 (2003)

33. Bede, B, Gal, SG: Generalizations of the differentiability of fuzzy-number-valued functions with applications to fuzzy differential equations. Fuzzy Sets Syst. 151, 581-599 (2005)

34. Alikhani, R, Bahrami, F, Jabbari, A: Existence of global solutions to nonlinear fuzzy Volterra integro-differential equations. Nonlinear Anal. TMA 75(4), 810-1821 (2012)

35. Allahviranloo, T, Hajighasemi, S, Khezerloo, M, Khorasany, M, Salahshour, S: Existence and uniqueness of solutions of fuzzy Volterra integro-differential equations. In: Information Processing and Management of Uncertainty in Knowledge-Based Systems. Applications. Communications in Computer and Information Science, vol. 81 pp. 491-500 (2010)

36. Bede, B: A note on 'Two-point boundary value problems associated with non-linear fuzzy differential equations'. Fuzzy Sets Syst. 157(7), 986-989 (2006)

37. Bede, B, Rudas, IJ, Bencsik, AL: First order linear fuzzy differential equations under generalized differentiability. Inf. Sci. 177, 1648-1662 (2007)

38. Bede, B, Stefanini, L: Generalized differentiability of fuzzy-valued functions. Fuzzy Sets Syst. 230, 119-141 (2013)

39. Chalco-Cano, Y, Román-Flores, H: On new solutions of fuzzy differential equations. Chaos Solitons Fractals 38 , 112-119 (2008)

40. Lupulescu, V: Initial value problem for fuzzy differential equations under dissipative conditions. Inf. Sci. 178(23), 4523-4533 (2008)

41. Malinowski, MT: Random fuzzy differential equations under generalized Lipschitz condition. Nonlinear Anal., Real World Appl. 13(2), 860-881 (2012)

42. Malinowski, MT: Existence theorems for solutions to random fuzzy differential equations. Nonlinear Anal. TMA 73(6), 1515-1532 (2010)

43. Malinowski, MT: On random fuzzy differential equations. Fuzzy Sets Syst. 160(21), 3152-3165 (2009)

44. Stefanini, L, Sorini, L, Guerra, ML: Parametric representation of fuzzy numbers and application to fuzzy calculus. Fuzzy Sets Syst. 157, 2423-2455 (2006)

45. Mizukoshi, MT, Barros, LC, Chalco-Cano, Y, Román-Flores, H, Bassanezi, RC: Fuzzy differential equations and the extension principle. Inf. Sci. 177, 3627-3635 (2007)

46. Malinowski, MT: Strong solutions to stochastic fuzzy differential equations of Itô type. Math. Comput. Model. 55, 918-928 (2012)

47. Malinowski, MT: Itô type stochastic fuzzy differential equations with delay. Syst. Control Lett. 61, 692-701 (2012)

48. Malinowski, MT: Some properties of strong solutions to stochastic fuzzy differential equations. Inf. Sci. 252, 62-80 (2013)

49. Malinowski, MT: Approximation schemes for fuzzy stochastic integral equations. Appl. Math. Comput. 219 11278-11290 (2013)

50. Malinowski, MT: On a new set-valued stochastic integral with respect to semimartingales and its applications. J. Math Anal. Appl. 408, 669-680 (2013) 
51. Malinowski, MT: Modeling with stochastic fuzzy differential equations. In: Chakraverty, S (ed.) Mathematics of Uncertainty Modeling in the Analysis of Engineering and Science Problems, pp. 150-172. IGI Global, Hershey (2014)

52. Agarwal, RP, Arshad, S, O'Regan, D, Lupulescu, V: Fuzzy fractional integral equations under compactness type condition. Fract. Calc. Appl. Anal. 15, 572-590 (2012)

53. Arshad, S, Lupulescu, V: On the fractional differential equations with uncertainty. Nonlinear Anal. TMA 74(11) 3685-3693 (2011)

54. Arshad, S, Lupulescu, V: Fractional differential equation with fuzzy initial condition. Electron. J. Differ. Equ. 2011, 34 (2011)

55. Allahviranloo, T, Salahshour, S, Abbasbandy, S: Solving fuzzy fractional differential equations by fuzzy Laplace transforms. Commun. Nonlinear Sci. Numer. Simul. 17(3), 1372-1381 (2012)

56. Allahviranloo, T, Abbasbandy, S, Sedaghatfar, O, Darabi, P: A new method for solving fuzzy integro-differential equation under generalized differentiability. Neural Comput. Appl. 21(1), 191-196 (2012)

57. Allahviranloo, T, Amirteimoori, A, Khezerloo, M, Khezerloo, S: A new method for solving fuzzy Volterra integro-differential equations. Aust. J. Basic Appl. Sci. 5(4), 154-164 (2011)

10.1186/1687-1847-2014-177

Cite this article as: Hoa et al.: Interval-valued functional integro-differential equations. Advances in Difference Equations 2014, 2014:177

\section{Submit your manuscript to a SpringerOpen ${ }^{\circ}$ journal and benefit from:}

- Convenient online submission

- Rigorous peer review

- Immediate publication on acceptance

- Open access: articles freely available online

- High visibility within the field

- Retaining the copyright to your article 